\title{
Design a Civil Engineering Micro-lecture Platform based on the ARCS Model Perspective
}

\author{
https://doi.org/10.3991/ijet.v12i01.6487 \\ Wenting Zhang \\ Chang'an University, Xi'an, Shaanxi, China \\ zhangwenting201611@126.com
}

\begin{abstract}
Based on ARCS model theory, this paper designed a microlecture teaching platform. Due to the integration of Android and SQL Server technology and ARCS model theory, the platform can carry out teaching practice on intelligent mobile devices, and has some features like mobility, seamlessness and strong advancement. At the same time, the course of civil engineering in universities and colleges was taken as an example to test the practical value of this mobile teaching platform. The ARCS motivation model based micro-lecture platform pays attention to the stimulation and maintenance of learners' motive, focuses on the interest in learning, and strengthens and keeps the interest of learners through a series of strategies to achieve the purpose of learning. It is helpful for changing the present situation in teaching that the level of learners' learning motivation is weakening, and thereby has certain reference significance for the design of learning-oriented teaching software, especially self-learning teaching software.
\end{abstract}

Keywords-ARCS model, Android technology, SQL server technology, civil engineering, micro-lecture platform

\section{$1 \quad$ Introduction}

The 21st century is an era of information and knowledge economy. Education for all, quality education, personalized learning and lifelong learning have become some important features of education development in the information age. With the emergence of new teaching modes such as Khan Academy [1], MOOC [2] and Flipped Classroom [3], micro-lecture, as an important carrier of these new teaching modes at the content level, has also attracted more and more researchers and educators to pay attention to its design and development. With the recognition of human's attention duration and the limited scope of attention at the same moment, micro-lecture promotes the miniaturization of learning objectives, learning content and learning time design. At present, most researchers define "micro-lecture" as a series of microoriented micro-teaching content which is carefully designed to reach specific teaching 
objectives, uses micro-video expression, carries certain teaching activities, and has certain independence and relevance with each other [4].

\section{Review of Research Progress}

Micro-lecture first appeared at the 60-Second Course proposed by Professor LeRoy A. McGrew at the University of Iowa [5] and the One Minute Lecture (OML) put forward by T. P. Kee [6]. The concept of micro-lecture which is popular now was presented by David Penrose in 2008 [7]. He raised five steps of developing a microlecture: listing the core concepts of teaching, and writing a 15-30 second introduction and summary; providing the context and recording a 1-3 minute video for the core concepts; designing and guiding students to read or explore the after-school tasks related to the course knowledge; uploading the teaching video and course tasks to the course management system. Sweet el al. [8] made a comment on the application of micro-lectures in flapped classroom, and revealed their role of providing teachers with differentiated instruction and helping students become more responsible for their learning. They also included a list of resources for creating micro-lectures. Researchers [4] have examined the function of online formative tests (OFTs) enriched with hyperlinks to microscituations on examination scores. It was discovered that to prepare for the summative midterm exam, averagely $74 \%$ of all students used OFTs Students who have utilized OFTs in relation with micro-lectures obtain higher grades, especially in highly aligned summative tests. According to the instructional design model of Blending Learning, Han et al. [9] expounded the composition and principle of micro-lecture teaching design, as well as the basic from, essential elements and activity characteristics of micro-lecture network platform design. They followed the roles of teachers and students, teaching process and video recording in Blending Learning to classify micro-lectures, particularly analyzed the design of teachingoriented and demonstration-oriented micro-lectures, explored the application of micro-lecture video recording technology, and used it in multimedia teaching, achieving positive effects.

In the study, we found that there are still some shortcomings in both single microlectures and the integrated micro-lecture system. The first defect is the lack of awareness of learning among students. Micro-lecture is different from the conventional teaching, requiring students to consciously complete the study without supervision by the teacher. However, some students still remain in the previous learning model and suffer from the shortage of self-learning awareness. Secondly, the existing online video playing sites and teachers' personal blog space sites allow users to shoot and upload some video files. After being audited, these video files on the sites can be played by other student users on demand. This way is adopted to share some videos and images with students. Nonetheless, in the process above, teachers need to use the camera to capture images, store them in photographic memorizers, such as SD memory card, and then upload them to the online site they choose. The corresponding video can be played after being audited, but there is a certain gap of time between the formal time of playing the video under this play mode and the shooting time. Mean- 
while, this mode would sometimes impact the coherence of micro-lecture content, and thereby affect students' learning results.

To solve the aforementioned problems, this research proposed the design of civil engineering micro-lecture from the perspective of ARCS motivation model. It innovatively put forward the application of ARCS motivation model to design the whole micro-lecture teaching, and provided a method and system for instant video playing. The design can meet the demand for instant video playing among teachers and students, therefore drawing a wide range of concerns or clicks for micro-lecture learning among students.

\section{Theoretical Basis}

\subsection{ARCS motivation model}

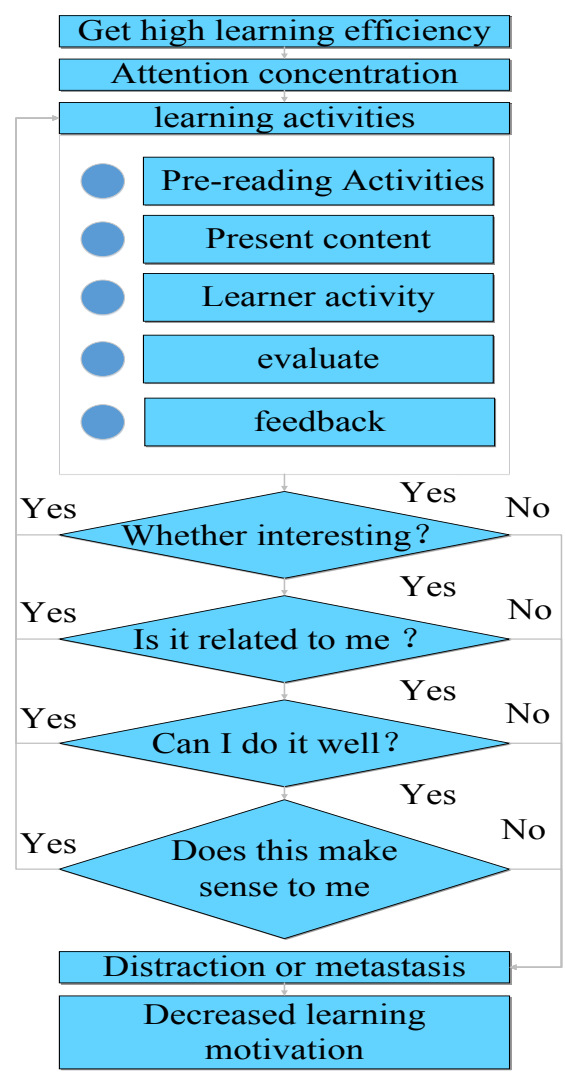

Fig. 1. Relationship between the three conditions in ARCS motivation model 
ARCS motivation model is developed on the basis of the theory of value, expectancy theory and such a basic assumption that if people perceive activities as satisfying their needs and have positive attitudes towards their own success, they will enjoy a higher degree of enthusiasm in activities [10]. To maintain learners' motivation, in addition to the first condition, it is necessary meet the following three conditions: Firstly, we must make learners realize that learning activities are closely related to them; secondly, learners believe that they are able to solve the problem through their own efforts; thirdly, learners can obtain psychological satisfaction in the process of completing tasks or from the result. The relationship is shown in Figure 1.

\subsection{Sub-goals of the civil engineering micro-lecture platform based on ARCS motivation model}

Clarity of micro-lecture goal orientation: From the perspective of ARCS model, the micro-lecture design should have clear goals. The content of each micro-lecture should point to a specific teaching difficulty or focus, provide a clearer teaching basis for learners, pay full attention to the hierarchy and diversity of every micro-lecture teaching objective, and focus on highlighting the clarity of micro-lecture goals in the teaching process.

Accuracy of the expression of micro-lecture goals: The expression of learning goals of micro-lecture based on ARCS model must be very accurate, to make learners clearer about the content and standards of learning evaluation after the completion of micro-lecture, which is conducive to their own academic level prediction and planning. In the acceptance and learning of the micro-lecture content, learners can constantly enhance their confidence, promote their learning focus, and ensure the quality of learning.

Association between micro-lecture and learners: According to ARCS model, when learning goals are closely related to learners' learning expectations and learning preparation, their desire for learning can be stimulated. Therefore, the design of the micro-lecture platform should incorporate learners' expectations into some details. For example, the construction of an interactive communication platform can allow learners to have the opportunity to write down their own ideas on the application of micro-lecture, so as to establish the link between micro-lecture and learners.

\section{The "Civil Engineering" Micro-lecture Platform Based on ARCS Motivation Model}

\subsection{Overall structure of the "civil engineering" micro-lecture platform}

In this study, ARCS motivation model was employed to the micro-lecture of Civil Engineering. The micro-lecture platform adopted the $\mathrm{C} / \mathrm{S}$ structure design pattern to construct the Andorid system based human-computer interaction interface. The server 


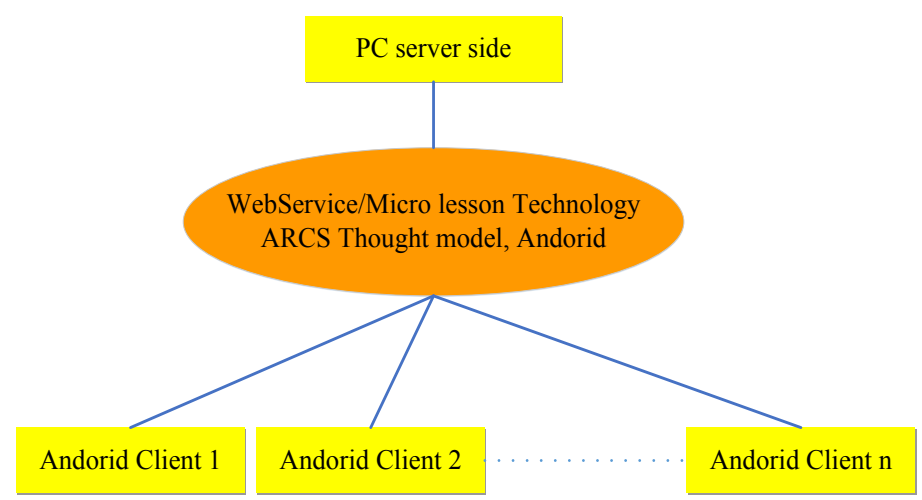

Fig. 2. Overall structure of the "civil engineering" micro-lecture platform (1)

of the platform was developed by JAVA and connected the structure through WebService. Figure 2 demonstrates the overall structure of the platform.

As shown in Figure 2, supported by the idea of micro-lecture technology, WebService and ARCS model, the entire platform connects the PC server and the Andorid client. Therefore, teachers can issue teaching instructions at the server side, while students can log on the micro-lecture platform via smart phone, to access ARCS model based teaching instructions issued by teachers and use the learning function provided by the platform for mobile online learning. The entire platform design has also learned from the experience of MVC model to create a sound user interface which is easy to operate and has impressive interactive features.

The hardware part is composed of the wireless module, camera, video data processing and other modules. By contrast, the software part contains Android system, JSON technology system, GSON technology system and SQL Server database. In addition, the idea of ARCS model was introduced into the software programming of the platform. The whole module function includes four systems, namely, Attention, Relevance, Confidence and Satisfaction. The structure diagram is shown in figure 3.

Based on the idea of ARCS motivation model, the overall module design of the whole teaching platform is shown in Figure 4.

As shown in Figure 4, the module of the whole platform is divided into four parts: registration login, course list, micro-lecture play and interactive communication. In practical design, the idea of ARCS model was introduced to customize specific software content for each module. For example, in the design of the registration login module, the "attention" theme was used. The entire interface uses the curriculum framework of "civil engineering" as the background, so that students will be immediately attracted by the interface content when they are registering or logging on the system, and therefore pay more attention to learning. As for the design of the interactive communication module, the theme of "satisfaction" was introduced. The userfriendly message board, voice interaction, online comment and other functions are helpful for increasing users' satisfaction, so as to reach the aim of improving learning experience. 


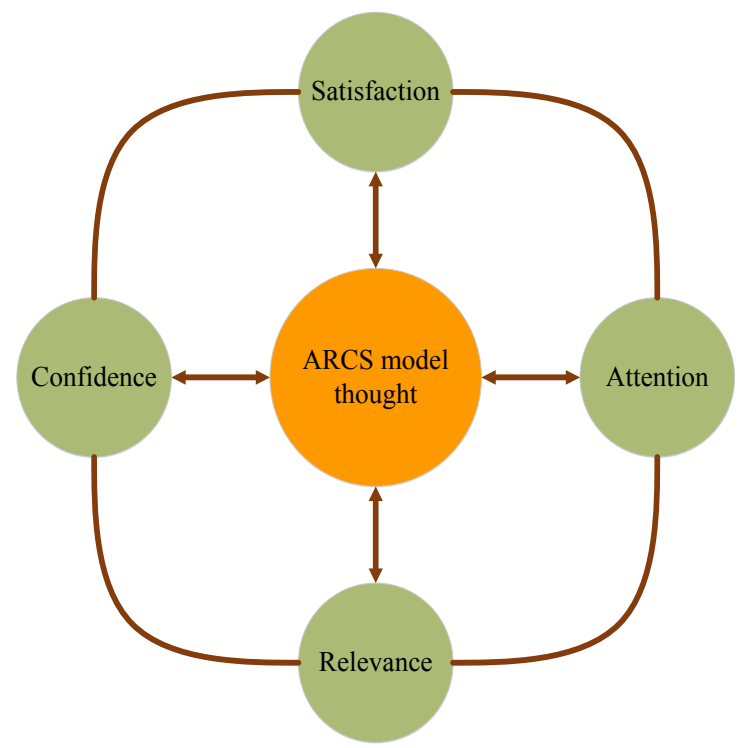

Fig. 3. Structure of the idea of ARCS model

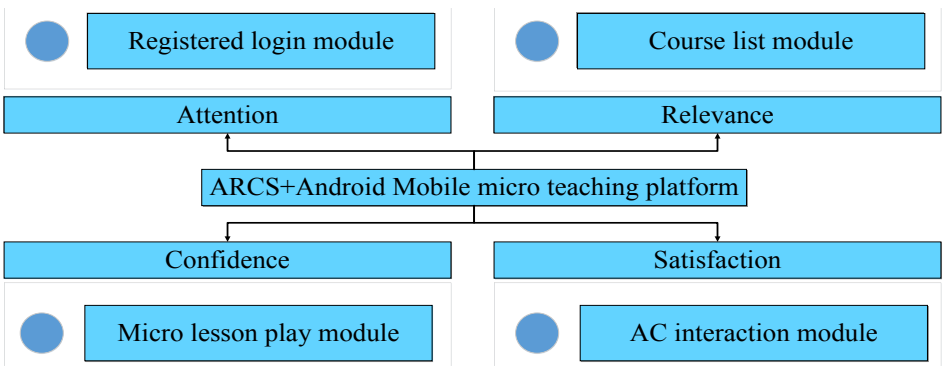

Fig. 4. Overall structure of the "civil engineering" micro-lecture platform (2)

\subsection{Development environment of the "civil engineering" micro-lecture platform}

The development of the platform is based on Android environment. In specific development of the platform, it is necessary to configure and build multiple environments, including operating environment of the system, server-side development environment, and Android client development environment. The following part gives more details.

The first step is the development of operating environment of the system. Both the system's Android client and WebServer server side are developed by using JAVA. In configuration, JDK/JRE program, which can be downloaded from Oracle's official 
website, should be installed and configured. A screenshot of the configuration process is given in Figure 5.

The second step is the development of server-side environment. The micro-lecture platform server is built by using WebServer. In the development process, MyEclipse should be used to configure the server-side program, and Web server should be constructed through Apache Tomcat 6.0.

The last step is the development of Android client environment. The client of the platform is based on Android system environment and developed by applying Eclipse software.

\section{Java}

\begin{tabular}{|c|c|c|c|c|c|c|c|c|c|c|c|c|c|}
\hline \multirow{12}{*}{ JDK } & \multirow{3}{*}{\multicolumn{2}{|c|}{$\begin{array}{r}\text { Java Language } \\
\text { Tools \& } \\
\text { Tool APIs }\end{array}$}} & \multicolumn{11}{|c|}{ Java Language } \\
\hline & & & \multirow{2}{*}{\multicolumn{2}{|c|}{\begin{tabular}{|c|c|} 
java javac \\
Security & Int'l \\
\end{tabular}}} & c javadoc & apt & jar & \multicolumn{2}{|c|}{ javap } & \multicolumn{2}{|l|}{ JPDA } & JConsole & $\begin{array}{c}\text { Java } \\
\text { VisualVM }\end{array}$ \\
\hline & & & & & RMI & IDL & Deploy M & \multicolumn{2}{|c|}{ Monitoring } & \multicolumn{2}{|c|}{ Troubleshoot } & Scripting & JVM TI \\
\hline & & $\begin{array}{l}\text { Deployment } \\
\text { rechnologies }\end{array}$ & \multicolumn{3}{|c|}{ Deployment } & \multicolumn{5}{|c|}{ Java Web Start } & \multicolumn{3}{|c|}{ Java Plug-in } \\
\hline & & \multirow{2}{*}{$\begin{array}{r}\text { User } \\
\text { Interface } \\
\text { Toolkits }\end{array}$} & \multicolumn{4}{|c|}{ AWT } & \multicolumn{4}{|c|}{ Swing } & \multicolumn{3}{|c|}{ Java 2D } \\
\hline & & & \multicolumn{2}{|c|}{ Accessibility } & \multicolumn{2}{|c|}{ Drag n Drop } & \multicolumn{2}{|c|}{ Input Methods } & \multicolumn{2}{|c|}{ Image I/O } & \multicolumn{2}{|c|}{ Print Service } & Sound \\
\hline & & $\begin{array}{l}\text { Integration } \\
\text { Libraries }\end{array}$ & IDL & & JDBC & & \multicolumn{2}{|l|}{ JNDI } & RMI & & \multicolumn{3}{|c|}{ RMI-IIOP } \\
\hline & \multirow{5}{*}{ JRE } & & \multicolumn{2}{|l|}{ Beans } & \multicolumn{2}{|c|}{ Intl Support } & \multicolumn{2}{|c|}{ Input/Output } & JMX & & \multicolumn{2}{|r|}{ JNI } & Math \\
\hline & & $\begin{array}{l}\text { Other Base } \\
\text { Libraries }\end{array}$ & \multicolumn{2}{|c|}{ Networking } & $\begin{array}{l}\text { Override } \\
\text { Mechanisn }\end{array}$ & & \multicolumn{2}{|c|}{ Security } & Serializa & ation & \multicolumn{2}{|c|}{$\begin{array}{l}\text { Extension } \\
\text { Mechanism }\end{array}$} & XML JAXP \\
\hline & & lang and util & \multicolumn{2}{|c|}{ lang and util } & Collections & \multicolumn{2}{|c|}{$\begin{array}{c}\text { Concurrency } \\
\text { Utilities }\end{array}$} & & JAR & Logg & & Manas & gement \\
\hline & & Libraries & $\begin{array}{c}\text { Preferenc } \\
\text { API }\end{array}$ & ces & $\begin{array}{c}\text { Ref } \\
\text { Objects }\end{array}$ & & flection & $\begin{array}{r}R \in \\
\text { Expr }\end{array}$ & $\begin{array}{l}\text { egular } \\
\text { ressions }\end{array}$ & Versio & ning & Zip Instru & umentation \\
\hline & & $\begin{array}{l}\text { Java Virtual } \\
\text { Machine }\end{array}$ & & Java & Hotspot Clie & ent VN & & & & Java Ho & spot & t Server VM & \\
\hline & & Plattorms & & olaris & & & nux & & Winc & adows & & & Dther \\
\hline
\end{tabular}

Fig. 5. Screenshot of the JDK/JRE configuration process

\subsection{Instant paly technology of the "civil engineering" micro-lecture platform}

When a micro-lecture is being recorded, the device can establish a connection with the website through the wireless network; then, the website can authenticate the video device. If the authentication fails, the website notifies the video device that the authentication fails. If the authentication is passed, the video device will make the video, subdivide the video data, and process the subdivided video data into video stream and upload it to the website through the wireless network. The website assigns a playback control to the video stream, establishes a corresponding play window for the video, puts the play window on the corresponding play page and plays the video instantly. 
Secondly, the video data recorded in the micro-lecture platform are divided into blocks and synthesized. The data blocks synthesized are converted into the video stream and then uploaded via the wireless network.

In addition, the video recorded in the micro-lecture platform also acquires the region information of the record device and writes the region information into the control field of the video stream. Then, all play windows are listed on the corresponding play page according to the reverse order of the time they were created. The structure of instant paly technology of the micro-lecture platform is shown in Figure 6. Part of the operation process is shown in Figure 7.

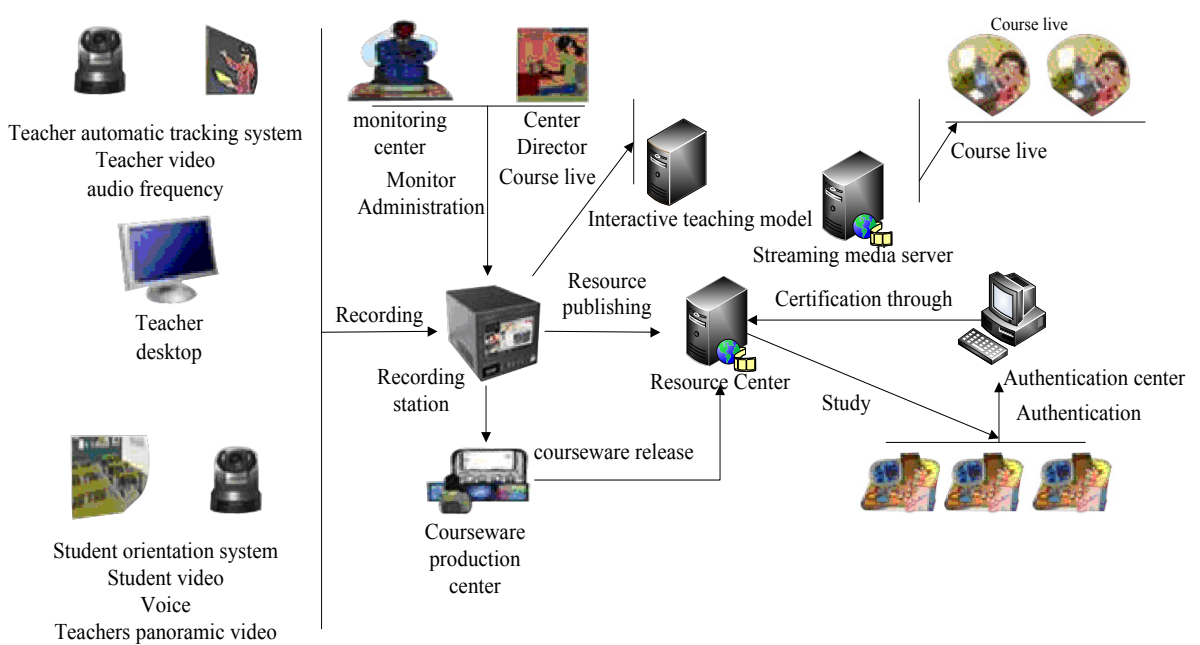

Fig. 6. Structure of instant paly technology of the "civil engineering" micro-lecture platform

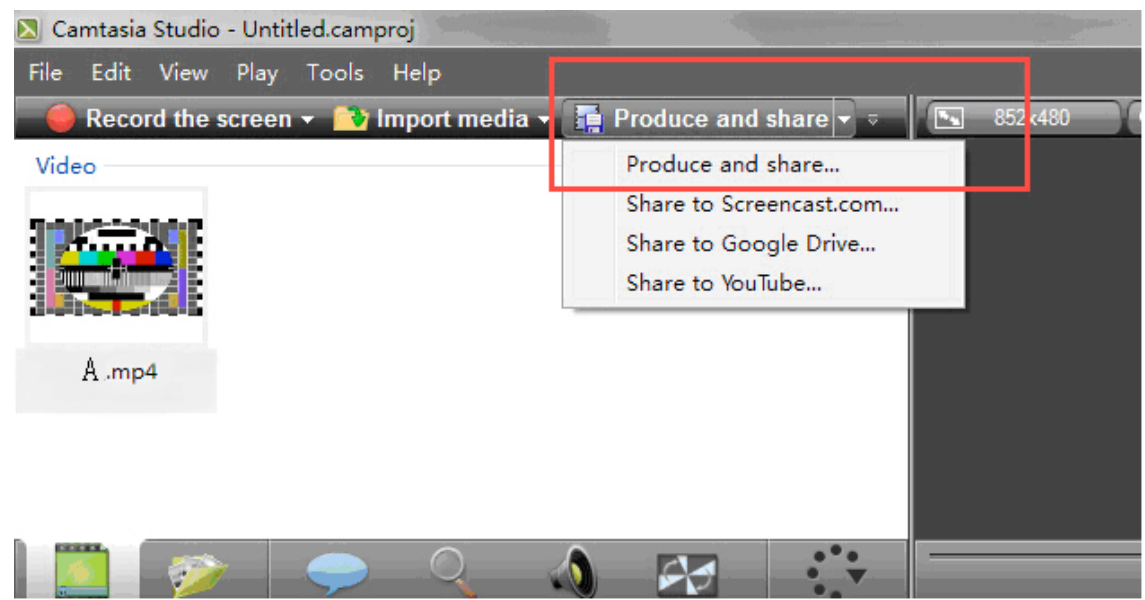

Fig. 7. Screenshot of instant paly technology of the "civil engineering" micro-lecture platform 


\subsection{Implementation of the civil engineering micro-lecture interface}

As mentioned previously, the module of this platform mainly include: registration login, course list, micro-lecture play and interactive communication. The compilation idea of these modules is based on ARCS, uses the kernel of Android system, and integrates the application of GSON and JSON technology. The specific implementation of the compilation process for each module is given in the following part:

Registration login interface: The registration module is used to realize the registration by news user and logon by old users, and can provide the logon help for users with different permission. The interface module is based on Android system platform. Notably, users can download and install the APP through smartphone.

Micro-lecture play interface: The design and implementation of the micro-lecture play module introduces a real-time video paly technology. The technology can link the mobile network and the platform server through the wireless module. The server authenticates the user side. Once the authentication passes, the user can instantly download micro-lecture teaching resources from the platform server, and play them online on mobile phone. After the teacher and the student log on the system, they can have interactive teaching when the communication network is smooth. The forms to implement interaction mainly include text chatting, voice chatting and handwriting chatting via the interactive teaching whiteboard. Among them, the interactive teaching whiteboard is kind of online handwriting interactive software which covers free brush, color selection, content clearing and other functions.

\section{$5 \quad$ Test of Platform Effect}

After the design of the platform, Class (1) and Class (2) of Grade 2014 majoring in architecture engineering in Chang'an University, Shanxi, China, were selected to participate in the test. There were 50 students in these two classes respectively, and there was no significant statistical difference among students of the two classes in age, gender, learning ability and other indicators $(\mathrm{P}>0.05)$. In specific teaching experiment, Class (1) was treated as the control class, and Class (2) was viewed as the experimental class in teaching activities. In the design of the teaching plan, "civil engineering", the compulsory course of architecture engineering, was used as the content and consisted of 56 hours. The "ARCS+Android mobile micro-lecture teaching platform" was employed for teaching students in the experimental class. By contrast, the general teaching method was applied for the control class. At the end of the course, final exam results and teaching experience of the two classes were investigated to compare their learning effect.

After 56 hours of teaching, the teacher collected and sorted the learning indicators of students in the experimental class and the control class, and compared the teaching effect. $\mathrm{P}<0.05$ meant statistically significant difference. The following tables give the specific statistical results: 
Table 1. Comparison of exam results of the control class and the experimental class (score, $, \mathrm{X}+\mathrm{s})$

\begin{tabular}{lll}
\hline \multicolumn{1}{c}{ Class } & \multicolumn{1}{c}{ Results of theory exam } & \multicolumn{1}{c}{ Results of practice exam } \\
\hline Experimental class & $97.34+6.54$ & $90.21+5.32$ \\
Control class & $67.72+3.22$ & $60.51+4.12$ \\
$\mathrm{t}$ & -2.445 & -3.567 \\
$\mathrm{p}$ & 0.001 & 0.003 \\
\hline
\end{tabular}

Table 2. Comparison of questionnaire survey results of the experimental class and the control class $(\%)$

\begin{tabular}{|c|c|c|c|c|c|c|}
\hline \multicolumn{2}{|c|}{ Class } & \multirow{2}{*}{$\begin{array}{c}\begin{array}{c}\text { Learning } \\
\text { interest }\end{array} \\
85\end{array}$} & \multirow{2}{*}{$\begin{array}{c}\begin{array}{c}\text { Knowledge } \\
\text { mastery }\end{array} \\
90\end{array}$} & \multirow{2}{*}{$\begin{array}{c}\begin{array}{c}\text { Active } \\
\text { learning }\end{array} \\
75\end{array}$} & \multirow{2}{*}{$\begin{array}{l}\text { Self help } \\
80\end{array}$} & \multirow{2}{*}{$\begin{array}{l}\begin{array}{c}\text { Knowledge } \\
\text { consolidation }\end{array} \\
87\end{array}$} \\
\hline & Good & & & & & \\
\hline \multirow[t]{3}{*}{ Experimental class } & General & 10 & 5 & 15 & 15 & 10 \\
\hline & Relatively poor & 5 & 5 & 10 & 5 & 3 \\
\hline & Good & 45 & 55 & 40 & 60 & 40 \\
\hline \multirow[t]{2}{*}{ Control class } & General & 25 & 30 & 35 & 30 & 35 \\
\hline & Relatively poor & 30 & 15 & 25 & 10 & 25 \\
\hline
\end{tabular}

First of all, from the exam results shown in Table 1 and Table 2, it can be known that the experimental class and the control class students had obvious statistical difference. Either in terms of the theory exam results, or the practice exam results, students of the experimental class were significantly better than their counterparts in the control class $(\mathrm{P}<0.05)$. Secondly, as revealed in the results of questionnaire survey, students in the experimental class were also better than those in the control class. Especially with regard to the indicator of "knowledge mastery", the rate of "good" in the experimental class was $90 \%$, in contrast with $55 \%$ in the control class, which implies that the application of the "ARCS+Android mobile micro-lecture teaching platform" in teaching is helpful for students to master the knowledge of "civil engineering", and has positive teaching effect.

"Civil Engineering" is a compulsory course of architectural engineering in colleges and universities. It aims to cultivate qualified technical talents of construction engineering, deepen students' understanding of the nature of civil engineering theory and practice, assist them to master the basic law of building, and improve their ability to analyze and solve related problems by using professional knowledge of architectural engineering. Nowadays, most teachers use the traditional multimedia teaching method in colleges and universities to organize teaching activities in the teaching of "civil engineering" of architecture engineering. This mode focuses on the application of PPT by the teacher, combined with on-site instruction, while students are responsible for watching and learning. In the whole teaching process, the initiative of students cannot be effectively mobilized, leading to low effectiveness of teaching.

The "ARCS+Android mobile micro-lecture teaching platform" designed in this paper is based on four motivation factors, including Attention, Relevance, Confidence and Satisfaction. It enables both teachers and students to conduct online teaching via 
intelligent mobile device. The characteristics of its application in teaching are also reflected in the following aspects: (1) The learning experience is enhanced. The ARCS model theory based system is built on Android mobile platform. Learners can use their smart phones and tablet computers to engage in mobile online learning. Since the convenience and efficiency of learning are greatly improved, the learning experience is naturally good. (2) Learning sharing becomes more convenient. The platform could not only realize the functions of online learning and self-learning, but can also download and store learning resources, effectively facilitate after-class review, and build a modern and informative "warm and new" system to achieve better results. (3) In this study, the micro-lecture instant recording and paly system can ensure the continuity of the teaching content, and the continuity of the videos played. It guarantees the learning effect among students in micro-lecture learning, and indirectly improves their learning interest. Due to the three characteristics above, students in the experimental class perceived more diverse learning experience than the control class in the learning process. Consequently, students of the experimental class obtained better learning effect.

\section{Conclusion}

With the development of computer-aided teaching technology, the practical effect of micro-lectures has become a growing concern. This paper constructed a microlecture teaching platform based on ARCS motivation model to stimulate and maintain leaners' motivation. It not only focuses on the improvement of teaching effect, but also attaches great importance to the interest of learning. Noticeably, it strengthens and maintains learner's interest through a series of strategies, so as to achieve the purpose of learning. In this study, the strategy ranging from attention, relevance, confidence and satisfaction can arouse and keep learners' motivation, to improve the quality and efficiency of teaching and learning. It is helpful to change the present situation that the level of learners' learning motivation is weakening and promote the teaching effect. Undoubtedly, it is of great significance for the design of learning software, especially for self-learning.

\section{$7 \quad$ References}

[1] Parslow, G.R. "Commentary: The Khan academy and the day - night flipped classroom," Biochemistry and Molecular Biology Education, vol. 40, no. 5, pp. 337-338, September 2012. https://doi.org/10.1002/bmb.20642

[2] Breslow, L., Pritchard, D.E., DeBoer, J., Stump, G.S., Ho, A.D., \& Seaton, D.T. "Studying learning in the worldwide classroom: Research into edX's first MOOC," Research \& Practice in Assessment, no. 8, pp. 13-25, August 2013.

[3] Herreid, C.F., Schiller, N.A., Herreid, K.F., \& Wright, C.B. "A chat with the survey monkey: case studies and the flipped classroom," Journal of College Science Teaching, vol. 44, no. 1, pp. 75-80, September 2014. https://doi.org/10.2505/4/jcst14 0440175

[4] Bouwmeester, R.A., De Kleijn, R.A., Freriksen, A.W., Van Emst, M.G., Veeneklaas, R.J., Van Hoeij, M.J., ... \& Van Rijen, H.V. "Online formative tests linked to microlectures improving academic 
Paper-Design a Civil Engineering Micro-lecture Platform based on the ARCS Model Perspective

achievement," Medical teacher, vol. 35, no. 12, pp. 1044-1046, August 2013. https://doi.org/10.3109/0142159X.2013.818633

[5] McGrew, L.A. “A 60-second course in organic chemistry,” Journal of Chemical Education, vol. 70, no. 7, pp. 543, July 1993. https://doi.org/10.1021/ed070p543

[6] Whittard, D. "Reflections on the one-minute paper," International Review of Economics Education, no. 20, pp. 1-12, September 2015.

[7] Clair, R.S. "Rimbaud et la Commune. Microlectures et perspectives (review)," Nineteenth-Century French Studies, vol. 41, no. 1, pp. 181-184, February 2012. https://doi.org/10.1353/ncf.2012.0040

[8] Sweet, D. "Microlectures in a flipped classroom: Application, creation and resources," Mid-Western Educational Researcher, vol. 26, no. 1, pp. 52-59, February 2014

[9] Han, Z.B. \& Han, K.L. "Research on Design of Micro-lecture Based on Blending Learning," Modern Educational Technology, no. 1, pp. 53-59, January 2014.

[10] Li, L.Y., Xu, R., \& Zheng, Y.L. "Design of Network Learning Feedback Based on ARCS Model," Modern Distance Education, no. 3, pp. 66-71, June 2013.

\section{Author}

Wenting Zhang is a Lecturer of School of Architecture, Chang'an University, Xi'an 710061, Shanxi, China. Her research interests include Civil Engineering and Micro-lecture Platform. (zhangwenting201611@126.com)

Submitted 03 December 2016. Published as resubmitted by the authors 16 January 2017. 